\title{
Cooking up Fine Remedies: On the Culinary Aesthetic in a Sixteenth-Century Chinese Materia Medica
}

\author{
VIVIENNE LO and PENELOPE BARRETT*
}

Flesh of the Quail

Sweet, bland, non-poisonous.

Not to be eaten before the month of May, eaten with pig's liver it will cause blackheads, with mushrooms one develops haemorrhoids.

A visceral tonic and vitalizer. Makes the bones and muscles strong and able to endure cold and heat. It relieves inflammation. With ginger and red mung bean it cures diarrhoea and dysentery. Fried in cream it is fattening to the belly, but it is good for reducing the abdomen swollen on account of water retention. For the chronic disorders of children. ${ }^{1}$

\section{Introduction}

In sixteenth-century Europe, Thomas Cogan (1545-1607), Andrew Boorde (1490-1549) and Jan Baptista van Helmont (1577-1644) ranged themselves on opposing sides in a debate as to the value of the arts of the kitchen for the learned physician. For those physicians committed to Galen's therapeutics, a correct daily regimen was essential preventive medicine. Boorde believed that "A good coke is halfe a physycyon. For the chefe physycke (the counseyll of a physycyon excepte) doth come from the kytchyn", 2 and Cogan referred to "cunning Cookes, or to the learned Physitian, who is or ought to be a perfect Cooke in many points". 3 For the Helmontians, who preferred a medical system

(C) Vivienne Lo and Penelope Barrett 2005

* Vivienne Lo, $\mathrm{PhD}$, and Penelope Barrett, The Wellcome Trust Centre for the History of Medicine at UCL, 210 Euston Road, London NW1 2BE, UK.

Many friends and colleagues have helped us in the preparation of this paper. We would particularly like to thank Eugene Anderson, Janet Browne, Paul Buell, Catherine Despeux, Joanna Grant, Geoffrey Lloyd, Vivian Nutton, Roel Sterckx, Andrew Wear, Zheng Jinsheng and all those at the Li Shizhen conference at the Needham Research Institute, where this paper was originally presented. All errors are naturally our own.

${ }^{1}$ Li Shizhen 李時珍 (Ming), Bencao gangmu 本草綱目, Xin jiaozhu ben, ed. Liu Hengru et al., 2 vols, Beijing, Huaxia chubanshe, 2002 (hereafter BCGM), vol. 2, 47 juan, p. 1731 , tr. Bernard E Read, Chinese materia medica: avian drugs, Peiping, Peking Natural History Bulletin, Dec. 1932, (hereafter Read, Avian drugs), Rubric 278 (unpaginated). Our emphasis. As will be evident in the footnotes, we have made frequent use of Read's lively and authoritative English versions of BCGM, which reflect a lifetime's work on the subject. Where translations by Read were not available, or were too free for the purposes of this paper, we offer our own literal translations.

${ }^{2}$ Andrew Boorde, The first boke of the introduction of knowledge and a compendyous regyment, ed. F J Furnivall, Early English Text Society, Extra Series, 10 London, Early English Text Society, 1870, p. 277; from the edition of 1547. As quoted in Andrew Wear, Knowledge and practice in English medicine, 1500-1680, Cambridge University Press, 2000, p. 170.

${ }^{3}$ Thomas Cogan, The haven of health: chiefely gathered for the comfort of students, and consequently of all those that have a care of their health, amplified upon five words of Hippocrates, written Epid. 6, Labor, cibus, potio, somnus, Venus ... Hereunto is added a preservation from the pestilence, with a short censure of the late sicknes at Oxford of Thomas Cogan, London, printed by Henrie Midleton, for William Norton, 1584 , p. 98 , as cited in Wear, op. cit., note 2 above, p. 170 . 


\section{Vivienne Lo and Penelope Barrett}

based on the chemical efficacy of simples, "the huckstery of the kitchin" was the base recourse of physicians "destitute of remedies and knowledge". 4

Meanwhile in Hubei province, central China, the physician and naturalist Li Shizhen 李時珍 (1518-1593) was finding satisfaction and status in compiling a materia medica with a distinctive culinary aesthetic. Though many basic medical interventions were beneath the Chinese scholar physician, whose physical contact with his patient might be limited to taking the pulse, experimentation with remedies and recipes was well within the remit of the élite practitioner. Of the 1,898 drugs and 11,096 prescriptions in Li Shizhen's monumental Bencao gangmu 本草綱目 (Systematic Materia Medica), he claims to have personally collected a total of 8,161 , many of which demonstrate appreciation and flair for fine food. ${ }^{5}$ But Li Shizhen was no menial kitchen empiric.

The pursuit of zhi wei 至味 (perfect flavour, or "sapor") ${ }^{6}$ was a key to social and political mastery in China - on the one hand as an analogy for good governance, and on the other to nourish the sage-ruler's own body as a conduit for Heaven's will. ${ }^{7}$ Lüshi chunqiu 呂氏春秋 (Mr Lü's Spring and Autumn), an encyclopaedia compiled under the auspices of Lü Buwei 吕不韋 (290-235 BCE), minister to the King of Qin, tells the story of one Yi Yin 伊尹. The King of Qin himself was destined to become first emperor of China in $221 \mathrm{BCE}$, and Lü Buwei was therefore at the epicentre of power in the third century BCE. Yi Yin is a semi-legendary figure, often described as a chef, who became minister to the first king of the Shang (1600-1045 вСE) on account of his culinary finesse. After engaging Yi Yin as an advisor, the sage ruler Tang 湯 performed a ritual purification with a burning torch and smeared his new recruit with the blood of a sacrificial pig. The next day in an inaugural speech, Yi Yin explained how, through delicate blending of the five sapors and feats of culinary alchemy, he could achieve zhi wei, a skill he likened to the "subtle arts of archery and horsemanship, the products of mixing Yin and Yang". For "when the inner self is complete, the [position of] Son of Heaven is complete. When the [position of] Son of Heaven is complete, the perfect sapors are supplied."

While Yi Yin describes neutralizing strong tastes and eulogizes purity, perfect sapor is attainable only in the combination of fragrant waters with exotic meats and fish, and fruits brought from all the lands over which the ruler holds sway, "the cress of Kunlun and the flower of the longevity Tree ... The finest of the seasoning agents are the ginger from Yangpu 陽樸; the cinnamon from Zhaoyao 招搖; the bamboo shoots from Yueluo 越駱; the

\footnotetext{
${ }^{4} \mathrm{~J}$ B van Helmont, Oriatrike: or, physick refined, trans. J[ohn B] C[handler] (1st ed., 1662), London, 1664, pp. 450-55, on p. 451, as quoted in Wear, op. cit. note 2 above, p. 402. Van Helmont did not value the skills required to blend a gentle and effective recipe. As representative of the Ancients in the debate between Ancients and Moderns, he developed a medical system based on the chemical principles of simples and was opposed to the Galenic physicians who served up compounds.

${ }^{5}$ Calculation from Paul Unschuld, Medicine in China: a history of pharmaceutics, Berkeley, University of California Press, 1986, p. 149. Li Shizhen
}

totals the number of recipes in the introduction to each of his sections.

${ }^{6}$ The translation of wei 味 as “sapor" emphasizes the range of medical as well as culinary virtues designated by the term.

${ }^{7}$ Roel Sterckx, 'Le pouvoir des sens: sagesse et perception sensorielle en Chine ancienne', in R Lanselle (ed.), Du pouvoir, Cahier du Centre Marcel Granet 1, Paris, Presses Universitaires de France, 2003, pp. 71-92; see also Roel Sterckx, 'Food and philosophy in early China', in Roel Sterckx (ed.), Of tripod and palate: food politics and religion in traditional China, London, Palgrave Macmillan, forthcoming 2005. 


\section{Cooking up Fine Remedies}

vinegar made from zhanwei 䲔鰖 sturgeon; the salt from Daxia 大夏; the dewy waters from Zaijie 芧揭, which have the colour of white jade; and the eggs from Changze 長澤".

$W e i$ 味 was much more than mere "taste". Carrying all the potency of their association with the wuxing 五行 (five agents: wood, fire, earth, metal, water), the five flavours/sapors were to extend a framework of knowledge that had structured astronomical, political, ritual and medical theory from early imperial times. ${ }^{9}$ At least from the seventh century onward, dietary authors systematically assigned both a sapor and a $q i$ to a food, qualities that were theoretically linked to therapeutic effect. A qi, in this medical context, was a thermostatic power: heating, warming, neutralizing, cooling or inducing cold. The sapors were pungent/ acrid, sweet, salt, sour and bitter. They also had the innate potential to stimulate different movements within the body. Thus heavenly, moral and physical categories were comprehensively drawn together into a distinctively Chinese cosmos, framing a very particular science of flavour. However, the activity of assigning medical properties to food is not in itself unique to China. Kenneth Albala observes that "most complex societies codify their foods investing in them a significance beyond satisfying hunger. In the West, at least since the ancient Greeks, this significance has been medical." ${ }^{10}$ In the same spirit of preventive medicine adopted in the Hippocratic "Regimen", Galen gave structure and coherence to the enduring belief that a good doctor should also be a good cook. ${ }^{11}$ On the properties of foodstuffs sets out the medical technology of that art. The "heat" of a food suggested that it would stimulate warmth in the body: for Galen, foxtail millet when made into bread was "poorly nourishing and cold", rocket, "obviously heating". ${ }^{12}$

The Greco-Roman associations of the bitter flavour with drying and warming, the sour flavour with drying and inducing cold, sweet with moistening and warming, and salty with moistening and inducing cold all seem to have a mirror in the Chinese correlations, but it is important to emphasize that these translations can only approximate the original Greek and Chinese terms. Moreover, as Geoffrey Lloyd has pointed out, a deep-seated ambivalence runs through these categories. ${ }^{13}$ Both Greek and Chinese theories were elaborated in medical literature dating to more than a millennium and a half before Li Shizhen or, for example, his contemporary the sixteenth-century Tübingen physician Leonhart Fuchs (1501-1566). Establishing the "power and effect" 14 of five hundred plants in his New herbal of 1543 , Fuchs relied on a theory of signatures current in his time and comparable, in

\footnotetext{
${ }^{8}$ Lüshi chunqiu 吕氏春秋 (Mr Lü’s Spring and Autumn): 14.2 Ben wei 本味 (Fundamental sapors), compiled under the auspices of Lü Buwei 吕不韋 (290-235 BCE). Translations taken or adapted from John Knoblock and Jeffrey Riegel, The annals of $L u$ Buwei, Stanford University Press, 2000, pp. 309-11. Lüshi chunqiu jiaoshi 呂氏春秋校䆁, compiled under the auspices of Lü Buwei (290-235 BCE), ed. Chen Qiyou 陳奇唒, Shanghai, Xuelin, 1984, p. 741

${ }^{9}$ Angus Graham, Disputers of the Tao, La Salle, ILL, Open Court, 1989, pp. 314-70.

${ }^{10}$ Kenneth Albala, 'Dietary regime in the Renaissance', in Malloch Room Newsletter, Jan. 1994, 7: 1-2.

${ }^{11}$ Mark Grant, Galen on food and diet, London, Routledge, 2000, p. 62.
}

\footnotetext{
${ }^{12}$ Owen Powell, Galen: On the properties of foodstuffs, Cambridge University Press, 2003, K524, p. 57 and K639, p. 106.

${ }^{13}$ See, for example, G E R Lloyd, The revolutions of wisdom, Berkeley and London, University of California Press, 1987, pp. 194-8. In a personal communication, Lloyd also stresses that the dominance of tetrads in the European tradition tends to be overstated. Although Galen favoured four humours, four elements and so on, there were many rival theories about which were the important humours-and what humours actually were.

14 "Power and Effect" is the rubric in each entry under which Fuchs describes the medical indications of the plants. See Leonhart Fuchs, The new herbal of 1543 (Das Kräuterbuch von 1543), Cologne and London, Verlag Taschen, 2001.
} 
Vivienne Lo and Penelope Barrett

Table 1

\begin{tabular}{llll}
\hline Earth & Sweet & Late summer & a \\
Metal & Pungent/acrid & Autumn & Harvest \\
Water & Salty & Winter & Preserve \\
Wood & Sour & Spring & Generate \\
Fire & Bitter & Summer & Grow
\end{tabular}

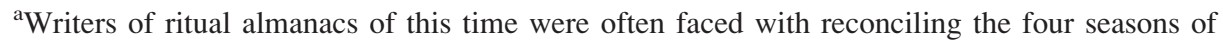
the agricultural year with the ritual year, which was divided into five to suit the five agent correspondences. The category of "late summer" was created to fit the ritual scheme, but often leads to structural anomalies. See John Knoblock and Jeffrey Riegel, The annals of Lu Buwei, Stanford University Press, 2000, p. 156.

its spirit of establishing sympathetic resonances, to the system of the five agents in China. ${ }^{15}$ The specific realization of this system varied, of course, from one culture to another, and within one culture, according to place and time.

The theory of the five agent correspondences (see Table 1 for correspondences relevant to this paper) was already an organizing principle in ritual texts, including dietary recommendations, documented in third-century BCE almanacs such as the manuscripts from Shuihudi 睡虎地 tomb 11 (burial dated c.217 BCE) and encyclopaedias like Lüshi chunqiu. In medieval texts, we have evidence of individual foods or medicines beginning to be comprehensively assigned medical properties, but it is not until the Yuan (1279-1368 CE) imperial dietary by Hu Sihui 忽思慧, Yinshan zhengyao 飲膳正要 (Propriety and Essentials in Eating and Drinking), that we see a tradition of recipes with a strong culinary aesthetic attached to entries in the materia dietetica. ${ }^{16}$

Ginger and garlic, onions, chives, leeks and hot pepper represent the pungent or acrid range of tastes that has no putative match among the four flavours of the European humoral tradition. "Pungent" might induce dispersing and expelling movements in the body, warming and stimulating qi. When related to the channels of moxibustion and acupuncture, pungent could enter the lung and large intestine channels, drying fluids and clearing mucus. ${ }^{17}$

Li Shizhen inherited this tradition of classification and made his own massive contribution to the theory and practice of Chinese pharmacology. He is eulogized today as one of the fathers of China's scientific research tradition on account of his reputed "empirical

\footnotetext{
${ }^{15}$ The theory of signatures is associated with the work of the Swiss naturalist Paracelsus (1493-1541).

${ }^{16}$ Knoblock and Riegel, op. cit., note 8 above, bks 1-12 and p. 309. For a discussion of the late medieval introduction of comprehensive systematic correspondences, see Ulrike Unschuld, 'Traditional Chinese pharmacology: an analysis of its development in the thirteenth century', Isis, 1977, 68: 224-48. See also Donald Harper, 'Iatromancy, diagnosis, and prognosis in early Chinese medicine', in Elisabeth Hsu (ed.), Innovation in Chinese medicine, Cambridge
}

University Press, 2001, pp. 99-120, on pp. 107-8. We follow Angus Graham in the translation of xing as "agents" rather than the more exclusive and temporal term "phases" in consideration of its wider connotations of active process, i.e. the quality of wetting and sinking associated with water or the flaming and rising associated with fire. Cf. Graham, op. cit., note 9 above, p. 326.

${ }^{17}$ Paul Buell and Eugene Anderson, A soup for the Qan, London and New York, Kegan Paul International, 2000, pp. 575-91. 


\section{Cooking up Fine Remedies}

spirit" and tireless dedication to his work. Joseph Needham calls him the "Prince of Pharmacists". ${ }^{18}$ Yet no portraits of the man pre-date the Red versus Expert controversies of the 1950s, when Mao Zedong was proclaiming that "Chinese medicine is a great treasure-house!" and waging war on the "bourgeois Western physicians" of the Ministry of Health. ${ }^{19}$ Those illustrations we have from that time and later resurrect him as socialist hero or kindly physician in the service of the masses. Despite the increasing number of modern hagiographies, there are few contemporary accounts of his life. What we know is largely based on Li Shizhen's son's prefatory note to his father's materia medica. ${ }^{20}$

Li's was a world of social mobility. The technological, political, and social changes of the Song (960-1279 CE), Jin (1127-1235 CE), and Yuan (1279-1368 CE) periods had profound implications for perceptions of medicine as a way of life and for the production of medical knowledge. Whereas medicine had hitherto been a relatively lowly profession, its status began to change from the time of the Yuan dynasty, when the Mongol government abolished the civil service examinations, and scholars who might previously have joined the government bureaucracy were forced to look for other ways of living. ${ }^{21}$ Medicine attracted more and more gentlemen, particularly in the Yangzi river area where Li lived, even after the civil service examinations were reintroduced under the Ming dynasty. Printing technologies stimulated the transmission of medical knowledge outside traditional family-based lineages: successive governments disseminated official editions of medical texts, and individuals published medical treatises as a way of accumulating moral and religious virtue. ${ }^{22}$ All these innovations preceded and came to bear on Li Shizhen's life.

There were also opportunities for upward social mobility. In two generations Li's family had risen from his grandfather's position as an itinerant ling yi 鈴醫, a "bell” doctor, in Hubei. Bell doctors were physicians who drew attention to themselves and the medical preparations they sold through their rhetorical abilities and by ringing a bell. ${ }^{23}$ His father before him had passed the basic level of civil service examinations and worked at the Imperial Medical Office. Li himself was a sickly child who failed to pass the examinations three times, but this did not bar him from high office. In the late 1540s, he was employed by the prince of Chu as physician and administrator to his court at Wuchang, and shortly afterwards he served at the Imperial Academy of Medicine in Beijing, before returning

\footnotetext{
${ }^{18}$ Joseph Needham, et al., Science and civilisation in China, vol. 6, Biology and botanical technology, part 1, Botany, Cambridge University Press, 1986, p. 308.

${ }^{19}$ Kim Taylor, 'Medicine of revolution: Chinese medicine in early Communist China, 1945-63', PhD thesis, University of Cambridge, 2000, pp. 108-83; see also Volker Scheid, Chinese medicine in contemporary China: plurality and synthesis, Durham, NC, Duke University Press, 2002, pp. 65-106, esp. p. 70.

${ }^{20}$ BCGM, vol. 1, p. 6.

${ }^{21}$ Robert Hymes, 'Not quite gentlemen? Doctors in Sung and Yuan', Chinese Science 1987, 8: 9-76; see also Asaf Goldschmidt, 'The Song discontinuity: rapid innovation in northern Song dynasty medicine', Asian Medicine: Tradition and Modernity, 2005, 1 (1): 53-90.

${ }^{22}$ Chen Hsiu-fen, 'Medicine, society, and the making of madness in imperial China',
}

$\mathrm{PhD}$ thesis, University of London, April 2003, p. 46; see also Yi-Li Wu, 'The bamboo grove monastery and popular gynecology in Qing China', Late Imperial China, June 2000, 21 (1): 41-76; see also Marta Hanson, 'Merchants of medicine: Huizhou mercantile consciousness, morality and medical patronage in seventeenth-century China', in Hashimoto Keizo, Catherine Jami and Lowell Skar (eds), East Asian science: tradition and beyond, Osaka, Kansai University Press, 1995, pp. 208-10.

${ }^{23}$ Paul Unschuld and Zheng Jinsheng, 'Manuscripts as sources in the history of Chinese medicine', in Vivienne Lo and Christopher Cullen (eds), Medieval Chinese medicine, London, RoutledgeCurzon, 2005, pp. $19-44$, p. 32. 


\section{Vivienne Lo and Penelope Barrett}

home where he worked as a doctor until his death in 1593. It was during this retirement from public service that he embarked upon his twenty-five-year project to create the definitive pharmacopoeia. In addition to trawling through the massive volume of literature listed at the beginning of his materia medica, he apparently also travelled widely in search of new remedies and to verify and extend his repertoire beyond his scholarly sources. ${ }^{24}$

Li grew up in a scholarly environment and was "a naturalist for whom the first tool [was] philology" ${ }^{25}$ Yet his status as a scholar physician did not put Li above acknowledging the kind of wisdom that every kitchen hand knows-for example, that $m u$ 鴊 ducks are best eaten between the Double Ninth Festival and Qingming Festival, because after that time they nest and grow thin ${ }^{26}$ or that gualuo 蝠螺 (helicoid snails) are collected and steamed in springtime when the flesh emerges from the shell, since after Qingming festival they become infested with insects. ${ }^{27}$ In one recipe in the "chives" section, he states that chive roots should be used in the winter months [when the fresh shoots are unavailable]. ${ }^{28}$

Li being only two generations from a "bell doctor", there were no doubt plenty of opportunities left for a wide range of hands-on medical work. Indeed, Li's devotion to his subject demanded a comprehensive exploration of available authorities, to which he contributed a critical eye and lucid commentary. After calling upon the wisdom of early and medieval canonical works, which generally precede and validate his own statements in each monograph, he uniquely uses the same format to cite himself, i.e. Shizhen yue 時珍曰 (Shizhen says). ${ }^{29}$ Thus while his research is not value-free, or independent of received morality, he aims to build on the past with his own beliefs and observations, thereby ranking his own name in the catalogue of medical authorities.

Growing up in the first half of the sixteenth century, Li was surrounded by rapid growth in agricultural technology and production, and in the manufacture of luxury products to satisfy a new urban-based commercial environment. New opportunities for travel, trade, and consumption created social pretensions and aspirations among the Ming élite that we will see manifested very clearly in Li's delight in haute cuisine. ${ }^{30}$ Through the innovative structure and style of Bencao gangmu prescriptions, this paper reviews how Li Shizhen's personal respect for, and love of, the culinary arts structured knowledge of the natural environment and simultaneously adjusted medical writing to the new social order.

\footnotetext{
${ }^{24}$ See BCGM, vol. 1, pp. 1-7 (various prefaces); Mingshi 明史, ed. Zhang Tingyu 張廷玉 et al., Beijing, Zhonghua shuju, 1974, vol. 25, 299 juan, p. 7653; L Carrington Goodrich and Chaoyang Fang (eds), Dictionary of Ming biography 1378-1644, New York and London, Columbia University Press, 1976, vol. 1, pp. 859-65; Lu, Gwei-Djen,

'China's greatest naturalist: a brief biography of $\mathrm{Li}$ Shih-chen', Physis, 1966, 8: 383-92; Needham, et al., op. cit., note 18 above, pp. 308-21; Nathan Sivin, 'Li Shih-chen', in Dictionary of Scientific Biography, New York, Charles Scribner's Sons, 1973, vol. 8, pp. 390-8; Chang Hui-chien, $L i$ Shih-chen-great pharmacologist, Beijing, Foreign Languages Press, 1960.

${ }^{25}$ Georges Métailié, 'The Bencao gangmu of Li Shizhen: an innovation in natural history?',
}

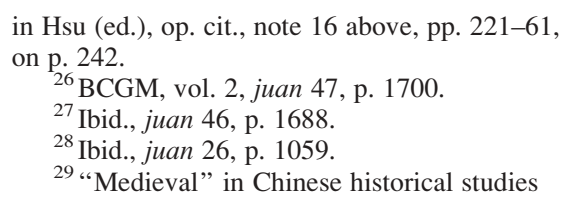
designates the period that roughly spans the fall of the Han dynasty in the third century CE to the tenth/ eleventh centuries after the fall of the Tang dynasty. Li Shizhen's self-citation is different in scope and function from Sima Qian's postscripts in Shiji. While Sima Qian also refers to himself in the third person - as taishi 太史 (Grand Historian)_Li is present in the text both as cited authority and as commentator.

${ }^{30}$ Timothy Brook, The confusions of pleasure: commerce and culture in Ming China, Berkeley, University of California Press, 1998. 


\section{Cooking up Fine Remedies}

\section{The Art of Compiling Remedies: Books, Classifications and Techniques. From Kitchen to Study?}

Before progressing to the main topic of this study, there are a number of fundamental questions concerning the historical boundaries of food and medicine to clarify. Li Shizhen is himself often explicit about the distinction between food and medicine: "The white horse is preferred in medicine" 31 or "In medicine, curds from cow's milk are considered best". 32 But what is the relationship between culinary and medical texts and classifications? To consider what makes one recipe medical and another culinary, we must first outline a relevant textual history, briefly introducing the literature of élite cuisine, the tradition of cookbooks and dietary recipes, the physician's materia dietetica, the pervasive and everchanging literature that deals with therapeutic food combinations and prohibitions. ${ }^{33}$

Until the recovery of 300 fragmented bamboo strips bearing culinary recipes from the tomb of Wu Yang 吳陽 (d. 162 BCE) at Huxishan 虎溪山 in Yuanling 沅陵, Hunan, it was thought that the realms of culinary and medical recipes were not clearly distinct in ancient China. ${ }^{34}$ A number of scholars had previously commented on the cooking evidenced in the medical recipe collections such as Wushi' er bingfang 五十二病方 (Fifty-Two Remedies), a text excavated from Mawangdui tomb 3 of the son of the Chancellor of Changsha (closed 168 BCE) in modern Hunan province, South China. Many of these remedies are "cooking preparations" in the sense that they use kitchen ingredients and methods:

Urine retention ... To treat it boil three sheng of black soybeans in three [...] of fine gruel vinegar. Cook rapidly. When it bubbles, stop the fire. When the bubbling subsides, cook again, stopping after it bubbles for the third time. Sieve to obtain the liquid. Use one portion of oysters and three of smithed dujin 毒堇—altogether two substances... ${ }^{35}$ Take one three-fingered pinch reaching to the knuckles, put it into lukewarm gruel vinegar, drink it. Drink before eating or after eating as you wish ... ${ }^{36}$

However, the culinary aesthetic informing these recipes is outshone by the Huxishan text. Most of the recipes are incomplete, but what remains gives a good impression of the whole:

... boil. When done, lift it out and discard the broth. Shake ... Take fresh sweet beef broth and add liquor, salt, meat sauce liquid, ginger, and magnolia (bark). Boil it again. When done,

\footnotetext{
${ }^{31}$ BCGM, vol. 2, 50 juan, p. 1817. Emphasis added.

${ }^{32}$ Ibid., 50 juan, p. 1829. Emphasis added.

${ }^{33}$ For a more complete summary of the literature, see Huang Hsing-tsung, Science and civilisation in China, vol. 6, Biology and biological technology, part 5, 'Fermentations and food science', Cambridge University Press, 2000, pp. 126-32.

${ }^{34}$ Tomb M1 was excavated in 1999. Wu Yang was one of the first generation of the family of the marquises of Yuanling. From the Shiji and Hanshu accounts, we know he was ennobled in 187 BCE and died in 162 BCE. The several hundred mortuary goods were poor in quality and reflected the general poverty of the area around Yuanling during the end of the Qin and beginning of Han dynasties. I am grateful to Zhang Chunlong 張春龍 for an unpublished report containing recipes, Zhang Chunlong and Guo Wimi,
}

\author{
'Yuanling Huxishan yihao Han mu zhujian \\ “Meishifang” ji xiangguan cailiao jieshao' \\ 沅陵虎溪山一號漢墓竹簡美食方及相關材料. See \\ the general description by Vivienne Lo, in a report on \\ the 'International academic conference on the \\ Changsha bamboo documents dating to $\mathrm{Wu}$ of the \\ Three Kingdoms: to celebrate one hundred \\ years of new discoveries and research into \\ bamboo strips and silk manuscripts', \\ 15-19 Aug. 2001, http://www.lib.uchicago.edu/ \\ earlychina/res/confrept/changsha.html \\ ${ }^{35}$ Dujin has not yet been identified. \\ ${ }^{36}$ Donald Harper, Early Chinese medical \\ literature: the Mawangdui medical manuscripts, \\ London, Kegan Paul International, 1998, \\ pp. 253-4.
}




\section{Vivienne Lo and Penelope Barrett}

lift it out and serve. The recipe for making boiled horse, boiled lamb, and boiled deer is like this. ${ }^{37}$

Wu Yang could undoubtedly contemplate a diverse and nourishing variety of foodstuffs and cooking techniques in his diet. In the surviving twenty of an estimated original 148 meat and fish and seven grain and vegetable recipes, we can see that the Han élite valued a varied diet with different methods of cooking rice, grain and vegetables, dog, goose, lamb, deer, pig, chicken, swallow, beef and hare. Different parts of the animals were cooked separately with a variety of techniques including steaming, braising, and potcooking, using alcoholic liquor, ginger and various ingredients for flavouring. The inclusion of this book in a tomb library that specialized in the calculations of wealth and influence aligns the culinary arts with other literary representations of power and status: at the corpse's head there was a register detailing the lands, households, staff, goods and chattels accumulated to the deceased in his lifetime, at his feet a rishu 日書 (day book) recording historical dates.

In conjunction with the Shennong Huangdi shi jing 神農黄帝食禁經 (Divine Farmer and Yellow Emperor's Culinary Prohibitions) recorded in the Hanshu 漢書 (58-76 CE) bibliography, the twenty or thirty titles relating to food literature, including Shi jing 食經 (Culinary Classics) and Shi fang 食方 (Culinary Remedies), that were kept in the imperial library of the Sui period (581-618 CE) furnish ample evidence of a range of nutritional literature circulating between early and medieval times in China. Some of the Shi jing and Shi fang are no doubt cookbooks, perhaps in the Huxishan tradition, despite the former being classified under medical literature. ${ }^{38}$ The 'Culinary Prohibitions' are one element of a structured literature of prohibition common to different medical traditions that dates back to the Han period, as we will see shortly.

From the tomb manuscripts, we learn that the Han élite were collectors of recipe literature and that this literature embraced both distinctively culinary and medical genres. Jia Sixie's 賈思妿 Q Qimin Yaoshu 齊民要術 (Essential Techniques for the Common People, c.540 BCE: 280 recipes in chapters 7-9) and Cui Hao's Shi jing 崔浩食經 (Cui Hao's Culinary Classic) are also gastronomic texts, in the sense that, like Wu Yang's cookbook, they display no explicit interest in therapeutic value and the treatment of illness, but rather focus on the technical problems of food production, with a homely concern for southern culinary finesse. ${ }^{39}$ Cui Hao, an astronomer, scientist and calendrical specialist, explicitly sets out to preserve the culinary traditions of the women in his family through times of hardship for later generations. Sadly only the preface survives. Jia Sixie's Qimin Yaoshu quotes from two sources, an unidentified Shi jing (Culinary Classic) and Shi ci 食次 (Culinary Procedures).

\footnotetext{
${ }^{37}$ Idem, 'The cookbook in ancient and medieval China', unpublished paper prepared for the conference on 'Discourses and practices of everyday life in imperial China', Columbia University, Oct. 2002.

${ }^{38}$ Ute Engelhardt, 'Dietetics in Tang China and the first extant works of materia dietetica', in Hsu (ed.), op. cit., note 16 above, pp. 173-92; Donald Harper, 'The cookbook in Ancient and Medieval China',
}

unpublished paper, 2002. See Hanshu 漢昰 (History of the former Han), juan 30, Ban Gu edition, Beijing, Zhonghua shuju, 1972, p. 1777; Sui shu 隋書, juan 34, ed. Wei Zheng et al., Beijing, Zhonghua shuju, 1973, p. 1043.

${ }^{39}$ Miao Qiyu 繆倁愉, Qimin yaoshu jiaoshi, Beijing, Nongye chubanshe, 1982, p. 458, n. 13; and p. 475, n.30, as quoted in Harper, op. cit., note 38 above. 


\section{Cooking up Fine Remedies}

With this documentary evidence of cookbooks from Han times, increasing from the Sui period onwards, it seems that the collecting, reading and compiling of culinary literature was a common activity for Chinese literati. Based on Shinoda's classical studies, H T Huang estimates that there were some seventy titles published before 1800 that conformed to the food canon and diet therapy traditions. ${ }^{40}$ Beyond the practicalities of food preparation, the culinary arts, as part of a body of knowledge that enhanced the life of the élite, might, like painting and poetry, be enjoyed for nostalgic reasons to do with times and places, to embellish educated discourse, insinuating a wealth of travel and culture in the reader and collector, or to ensure the continuity of lineage and tradition. In the following passage from Zhao hun 招魂 (Summons of the Soul) by Song Yu 宋玉 (third century $\mathrm{BCE}$ ), from the poetic corpus known as $\mathrm{Chu}$ ci 楚辭, the poet uses visions of rare delicacies to coax the soul of a sick lord back to his body.

O soul, come back! Why should you go far away? All your household have come to do you honour; all kinds of good food are ready: rice, broom-corn, early wheat, mixed all with yellow millet; bitter, salt, sour, hot and sweet: there are dishes of all flavours. Ribs of the fatted ox cooked tender and succulent; sour and bitter blended in the soup of $\mathrm{Wu}$; stewed turtle and roast kid, served up with yam sauce; geese cooked in sour sauce, casseroled duck, fried flesh of the great crane; braised chicken, seethed tortoise, high-seasoned, but not to spoil the taste; fried honey-cakes of rice flour and malt-sugar sweetmeats; jadelike wine, honey-flavoured, fills the winged cups; ice-cooled liquor, strained of impurities, clear wine, cool and refreshing; here are laid out the patterned ladles, and here is sparkling wine. ${ }^{41}$

\section{The Power of Gentle Remedies: Medieval Materia Dietetica}

Advocates of gentle remedies generally express a preference for preventive techniques grounded in the lifestyle of their particular culture. Following in the tradition of the Thracian physicians and the Hippocratic treatises that describe Greek regimen, Galen declared that the field of dietetics is the most valuable field of medicine. ${ }^{42}$ A revival of Galenic regimen aimed at preventing illness through leading "the simple life" can be detected in Sir John Harrington's affectionate translation of the Salernitan Rule, a medieval medical text in verse:

Use three Physicions still; first Doctor Quiet

Next Doctor Merry-man, and Doctor Diet. ${ }^{43}$

Quiet and diet feature as concerns of the early Chinese medical writers, but Doctor Merryman is often cast as a moral tutor. Roel Sterckx comments that "sense experience and sensory perception were valued as a genuine part of moral reasoning ..." [our emphasis]. ${ }^{44}$ Far from leading to indulgence and moral decline, a disposition for culinary finesse could demonstrate one's virtue in every sense of the word. Knowing the science of

\footnotetext{
${ }^{40}$ Huang, op. cit., note 33 above, p. 122.

${ }^{41}$ Tr. David Hawkes, Ch'u Tz'u: the songs of the south, Oxford, Clarendon Press, 1959, p. 107.

${ }^{42}$ Powell, op. cit., note 12 above, pp. ix, 4-5.

43 "Si tibi deficiant medici, medici tibi fiant/Haec tria, mens laeta, requies, moderata diaeta." Sir John
}

Harrington, The School of Salernum: Regimen sanitatis Salerni, English version, first publ. 1607, modern edition, Salerno, Ente provinciale per il turismo, 1953, p. 22.

${ }^{44}$ Sterckx, 'Le pouvoir', op. cit., note 7 above, pp. 71-92. 


\section{Vivienne Lo and Penelope Barrett}

good taste meant that, through diet, one could align physiological rhythms of the inner body with the seasons and by extension with the transformations of Heaven and Earth. An author or chef able to demonstrate this kind of sensually based virtue was a microtechnician of his own and others' bodies and by implication a medical thinker. ${ }^{45}$

Chefs at the imperial court and in great houses were, in theory at least, perfect masters of the art of harmonizing foods according to the season. The Rites of Zhou, for example, describes how the turtle officials, who were in charge of shellfish, prepared soft shelled turtles and clams for the emperor in spring, and turtles and fish in the autumn. ${ }^{46}$

Medical ideas about the flux and flow of the seasons were therefore structured by the five agent correlations. One should eat foods that support the season; thus in spring, liver $q i$ and the sapor "acid" or "sour" predominate, so one should eat foods from these categories. The sapors must also harmonize with the qi of the season. In the traditional mutual succession of the five sapors, each is combined in its season with the sapor "sweet", just as earth, the correlate of "sweet", from its central position, contains within itself the substances of the other agents. According to the Book of rites (Liji 禮記, compiled $c$. first century $\mathrm{CE}$ ?): "The five sapors, which are combined in six different ways to form the twelve types of dishes, follow on immediately from each other, and each in turn [according to the season] forms the basis of the food one takes." 47

A range of theories concerned with the therapeutic action of flavour are set out in Huangdi neijing. Rather than consistently affirming the principle of seasonal homeopathy, some indeed proposed the reverse: the sour sapor of spring might cause an excess which would damage the sinews (spring, sour and sinews are associated with the agent wood), and in such cases, it was deemed necessary to prescribe allopathically according to the cycle of domination that was thought to exist among the five agents. The same can be said for Greek medicine, where at least two points of view were current, that one used recipes to accord with the season or to counteract it. ${ }^{48}$

This is not to say that the early Chinese were above pleasure for pleasure's sake. Inevitably, there were many attitudes to what and how one should eat and when and why to pleasure oneself. Eating meat had ritual significance and was a sign of aristocracy, yet in the tomb libraries of the southern nobles, we find literature that recommends "giving up grains and eating $q i$ " as part of a culture of breath meditations. There are also cautionary words about over-eating.

$\ldots$ if the sage becomes fat and neglects boundaries, the stomach, the sinews and bone will not bear the burden. His $q i$ is too plentiful, his blood is excessive, the $q i$ and blood decay and fester, the hundred joints all sink, the twenty extremities empty and rebelling it goes to the heart. If these cannot be treated in advance then the sound of crying will be heard. ${ }^{49}$

\footnotetext{
${ }^{45}$ See, for example, the use of medicinal foods and moxibustion to cure the internal heat of a "gentleman" who has over-indulged in sex. Mawangdui Hanmu boshu 馬王堆漢堂㠳書, vol. 4, ed. Mawangdui Hanmu boshu zhengli xiaozu, Beijing, Wenwu chubanshe, 1985, p. 164.

${ }^{46}$ Catherine Despeux, 'Interdits de nourriture en Chine/Dietary prohibitions in China', trans. Penelope Barrett, unpublished paper.
}

\footnotetext{
${ }^{47}$ Zhouli 周澧, Shisanjing zhushu edition, ed. Ruan Yuan 阮元, Beijing, Yiwen yinshuguan, 2001, vol. 3, 5.72.

${ }^{48}$ Geoffrey Lloyd, personal communication.

${ }^{49}$ Zhangjiashan 247 hao Hanmu zhujian zhengli xiaozu, Zhangjiashan Hanmu zhujian 張家山漢墓竹簡, Beijing, Wenwu chubanshe, 2001 , p. 244
} 


\section{Cooking up Fine Remedies}

Not content with just combating degeneration of the body, for those with time and leisure in early China, a culture of yang sheng 養生 "nourishing life" meant that the body could be embellished and augmented, rendered more vital, its senses more astute or pleasured through a wide variety of dietary and therapeutic means. The remedy literature archived side by side with learned and theoretical medical treatises frequently serves as a foil to lofty discourses and provides a window on to a rich and eclectic culture of bodily practices.

Having outlined the difference between culinary and medical remedies in the second century BCE tomb literature above, it remains to say that there is one genre of remedy texts where we do find recipes with a natural feel for the finer kitchen arts. The power of tasty gentle remedies is most evident in the aphrodisiac recipes recovered from the Mawangdui tomb library, which aim at longevity and sustaining sexual pleasure:

Increasing Craving

... fuling (pine truffle) and discard the dregs. Use the liquid to fatten a suckling pig. Feed it to the woman. It makes her increase in sweetness and makes her inside become fine. Incinerate and smith the inner part of cow horn ... dried jiang (ginger) and jungui (curled cinnamon). Combine them ... put in a sack. Soak it in gruel vinegar and insert into the inside.

Another. Blend ... liquid with choice beef or venison. Have the woman insert it herself deep inside her prohibited part. $^{50}$

"Increasing craving" refers to improving the woman's sexual desire through the application and ingestion of fine food.

Embedded in medical attitudes, we often find censure of a society perceived to be in moral decline, and this is certainly the case for second century BCE China. Among the scanty evidence of real patients from this period, the twenty-five case histories of Chunyu $\mathrm{Yi}$ 淳於意 in Shiji 史記 (Records of the Historian) are remarkable in that they indict either sex and alcohol or both in the aetiology of some three-quarters of the male deaths. ${ }^{51}$ But it is drinking and eating to excess and not the enjoyment of fine things per se that was the subject of recurring censure, and the recipe tradition might be seen as one way of shaping and refining voracious appetites.

There are many criteria that come to bear on the shape of a recipe to which we will not have time to do credit here. But one important element that restricts and restrains Chinese food culture has already been hinted at in the Han title noted in the last section, 'Divine Farmer and Yellow Emperor's Culinary Prohibitions'. Many prohibitions are concerned with simple hygiene, with not eating spoiled and rotten meat. Others relate combinations to specific symptoms. We saw in the quotation at the head of this article, for example, Li Shizhen's comment that "eaten with pig's liver [quail] will cause blackheads, with mushrooms one develops haemorrhoids". Part of the adjustment of the diet to the environment consisted in blending ingredients and using flavours or sapors according to each season, as we have already seen. Both culinary and medical recipes are naturally

\footnotetext{
${ }^{50}$ Tr. Harper, op. cit., note 36 above, p. 336.

${ }^{51}$ Joanna Grant, A Chinese physician: Wang $J i$ and the 'Stone Mountain medical case histories', London, RoutledgeCurzon, 2003, pp. 128-9.
}

See also Elisabeth Hsu on this matter, 'Pulse diagnostics in the Western Han', in Hsu (ed.), op. cit., note 15 above, pp. 51-91, on p. 72. 


\section{Vivienne Lo and Penelope Barrett}

concerned that a plant or foodstuff be harvested or killed when it is at the optimum point in its life-cycle for enhancing potency or flavour. The "seasonal" in the culinary arts is thus partly grounded in the simple practicalities and local knowledge of the agricultural rhythms of the year, but there are also other criteria that structure the seasonal aesthetic in food.

Various types of literature concerned with ritual and religion, as well as calendrical texts, contain evidence of cycles and associations that also shaped dietary prohibitions and recommendations. Manuscript literature from Shuihudi, for example, contains the earliest prognostications that identify a variety of animal foodstuffs as the vector for disease caused by the vengeance of ghosts and deceased ancestors, keying the aetiology to specific days of the calendar.

When on jia 甲 and $y i$ 乙 days there is illness, the [deceased] father and mother are [the source of] the calamity. It is got through meat that is wrapped in lacquer implements to the east ...When on bing 丙 and ding 丁 days there is illness the father in law is [the source of] the calamity. The illness is got through red meat, cock, and wine ... When on ren 任 and gui 癸 days there is illness, when you do not meet people, an outside ghost is the [source of the] calamity. It is got through wine and slivers of dried and fresh meat served with vegetable and meat sauce. ${ }^{52}$

By medieval times there is an enormous extant literature detailing medical prohibitions, which embraces both acupuncture and the sexual arts. For the fifteenth day of the new moon, the Huangdi hama jing 黃帝蝦蟆經 (Yellow Emperor's Toad Canon) prohibits acupuncture and moxibustion at four locations on the body. It also prohibits "conjoining Yin and Yang", a euphemism for sexual intercourse. ${ }^{53}$

As Despeux points out:

[These] taboos pertained not only to foods themselves, but to the context in which they were consumed; the act of eating was surrounded by precautions, preparations and rituals. Food had social, symbolic and religious uses, in addition to its nutritive functions. ${ }^{54}$

Still committed to the gentle power of remedies as part of their work on materia medica, the eclectic medical authors of medieval China gathered together the knowledge of their predecessors and structured a dietary literature around the calendrical prohibitions, the associations with the five agents, Yin and Yang, and the movements of qi. The central figures were all literati at the hub of power in medieval China who seem to share some similarities in their career profiles and interests. Each, for example, held distinguished government posts and is associated, at least retrospectively, with a love of the reclusive life in the mountains, and the early organization of Daoism. In their work we can see the convergence of the themes of medicine, astronomy, alchemy and politics.

Tao Hongjing 陶弘景 $(452-536 \mathrm{CE})$, for example, was author of the pharmaceutical work Shennong bencao jing jizhu 神農本草經輯注 (Collected Commentaries on Shennong's Classic of Materia Medica) in which he edited and expanded the Han classic. His work formed the basis for Sun Simiao’s 孫思㯒 “Shizhi” 食治 (Food Therapy) chapter

\footnotetext{
${ }^{52}$ Liu Lexian 劉樂賢, Shuihudi Qinjian rishu уапjiи 睡虎地秦簢日書研究, Taibei, Wenjing chubanshe, 1993.

${ }^{53}$ Vivienne Lo, 'The Yellow Emperor's toad canon', in a special edition of Asia Major, essays
}

contributed in honour of Michael Loewe, ed. Nathan Sivin, 2001, 14 (2): 1-38; Donald Harper, 'Dunhuang iatromantic manuscripts: P. $2856 \mathrm{R}^{\circ}$ and P. $2675 \mathrm{~V}^{\circ}$, in Lo and Cullen (eds), op. cit., note 23 above, pp. 134-64.

${ }^{54}$ Despeux, op. cit., note 46 above. 


\section{Cooking up Fine Remedies}

in Beiji qianjin yaofang 備急千金要方 (Essential Prescriptions Worth a Thousand Gold Pieces for Emergencies, $c$. 652). ${ }^{55}$

Sun Simiao's great medical compendium contains an encyclopaedic treatment of the personal regimen that we have seen in the early Chinese self-cultivation tradition. He devotes large tracts to therapeutic traditions based on lifestyle recommendations from sexual techniques and breath meditations, to massage and medical gymnastics. Among his many contributions to Chinese medicine, Sun is remembered as the author of China's earliest extant code of medical ethics. He was a strong supporter of the gentle action of food prescribed as medicine, and his work provides us with a medieval source that organizes knowledge of the effects of food on the human being.

Emphasizing the importance of the sixty-three sections detailing dietary prohibitions attached to the entries in his dietetic, he provides a physiological explanation for the importance of correct food combinations:

If the $q i$ of different foods is incompatible, the vital essence will be damaged. The body achieves accomplishment thanks to the sapors that nourish it. If the different sapors of foods are not harmonized, the body becomes impure. This is why the sage starts off by obeying the alimentary prohibitions in order to preserve his nature; if that proves ineffective, he has recourse to remedies for sustaining life. ${ }^{56}$

After Tao Hongjing, Sun Simiao categorized foods as yang ming 養命 (nourishing heaven) or yang xing 養性 (nourishing nature), the two upper levels of the san pin 三品(three grades) of minerals or foodstuffs. These two he valued far more than the fast-action drugs attributed with $d u$ 毒 medical efficacy (also simply poison), which when taken for long periods would become poisonous. In a famous quotation, he compares strong drugs to the reckless attack of imperial soldiers, ${ }^{57}$ and he represents the general move towards milder drugs also endorsed by a new state sponsored materia medica, Tang xinxiu bencao 唐新修本草 (Newly Compiled Pharmacopoeia of the Tang Dynasty), and supported by a penal code indicting those physicians who harmed their patients.

Sun's work was extended further, with simple preparation methods and prescriptions, by his student Meng Shen 孟詵 (621-713) into the specialist work, Buyang fang 補湌方 (Prescriptions to Replenish and Nourish). Meng Shen was a polymath associated with the early organization of Daoism, and once vice-president of the imperial Department of Astronomy. In later life he retired to the mountains and devoted himself to yao' er 藥䬲 (medicinal foods). We know Meng's work from eighty-nine sections quoted in the earliest extant specialist materia dietetica, Zhang Ding's 張鼎 (eighth-century) Shiliao bencao 食療本草 (Materia medica for Dietary Therapy). ${ }^{58}$

Each monograph gives the particular actions of the herbs understood in terms of $q i$ and sapor, together with the main indications, food interdictions, and preparation methods. This was to set the pattern for later materia medica and dietetica.

From a fragment of Shiliao bencao recording twenty-five monographs (recovered in the Dunhuang cache of manuscripts (S.76)), and quotations in the Zhenglei bencao 證類本草

\footnotetext{
${ }^{55}$ Sun Simiao, Beiji qianjin yaofang, modern ed., Beijing, Renmin weisheng, 1955, juan 26, pp. 464-75.

${ }_{56}$ Ibid., p. 465 . Engelhardt, op. cit., note 38 above, pp. 181-4.
}

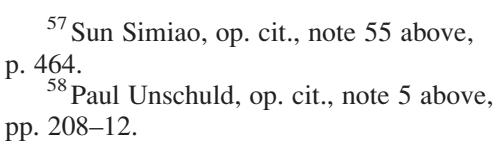




\section{Vivienne Lo and Penelope Barrett}

(Categorized Pharmacopoeia, 1108?) and Ishimpō 醫心方 (Remedies at the Heart of Medicine, 984), we know that both texts survived at least into the eleventh century. For the most part, the earlier materia dietetica record only the occasional rudimentary recipe:

Take one slice of mu gua 木瓜 (papaya or quince), seven leaves of mulberry, three large roasted jujubes, break open, boil in two large sheng of water, ${ }^{59}$ reducing it to half a large sheng. Bow the head and apply it ...60

Take three sheng of winter melon and remove the skin. Pound into pills ...

As we shall see, the recipes collected by Li Shizhen in Bencao gangmu are frequently both more complex and richer in concrete detail.

\section{Li Shizhen's Authority}

My father, Shizhen, was often ill as a child and was a dull student, but then he became addicted to the pleasures of books, which tasted as sweet to him as sugar-cane candy. ${ }^{61}$

What is most impressive about Li Shizhen's medical compendium is its sheer size. He was not the first to include culinary recipes in a materia medica, and his work is preceded by a lively tradition of specialist materia dietetica, in both Chinese and Greco-Roman medical traditions. Yet in the thirty years it took to compile Bencao gangmu, he mined the kitchens of China on an unprecedented scale, historically through the forty books and 277 authors identified in the list of books at the beginning of Bencao gangmu, and also through oral and technical traditions contemporary with him. ${ }^{62}$ In this, he draws a subjective authority from a combination of classical sources and personal experience.

Li Shizhen's scholarly work places him in the category of learned physician, but his was a culture which eulogized the culinary arts as appropriate knowledge in the service of power. Through gastronomic finesse, Li Shizhen's quotations and interjections serve to place him in a direct line of cultural descent from the Confucian sages. Echoing Mencius' love of "bear's paw", he states that, "Leopard placenta is one of the eight precious delicacies", and that yak meat tastes particularly delicious and "was classed with elephant steak as the finest of meats by $\mathrm{Mr} \mathrm{Lu}$ in the Chun qiu 春秋 [Spring and Autumn, c. $239 \mathrm{BCE}]$ ". 63

\footnotetext{
${ }^{59}$ This is an ancient Chinese measure, sometimes translated as a "pint" and approximately equivalent to 200 cubic centimetres. Ten sheng are equivalent to one $\mathrm{dou}$ 鬥.

${ }^{60}$ Ma Jixing (ed.), Dunhuang yiyao wenxian jijiao 敦煌醫藥文獻輯校 (The Dunhuang Medical Texts Edited and Collated), Nanchang, Jiangxi guji chubanshe, 1998 , p. 674.

${ }^{61}$ Preface to Li Shizhen, Bencao gangmu by his son Li Jianyuan 李建元, BCGM, vol. 1, p. 6.

${ }^{62}$ Métailié, op. cit., note 25 above, p. 222.

${ }^{63}$ BCGM, vol. 2,51 juan, p. 1850. Also translated in Bernard E Read, Chinese materia medica: animal
}

drugs, Peiping, Peking Natural History Bulletin, 1931 (hereafter Read, Animal drugs), Rubric 352 (unpaginated). Read adds that the other precious treasures are: "Phoenix marrow, bear's paws, ape's lips, dragon's liver, tail of the carp, roasted ox and cicada cheese. Some people include dromedary hump and deer's tail." Bernard Read's versions of Bencao gangmu have been our chief source for the identification of materia medica, supplemented by more recent medical and botanical reference works. BCGM, vol. 2, juan 51, p. 1857 


\section{Cooking up Fine Remedies}

Another example researched by the French sinologist Catherine Despeux is fish kuai 膾 (鱠), a dish with an illustrious pedigree normally prepared from raw fish and served with various condiments. The Book of rites, composed around the first century CE, says that it was eaten with chives in spring and mustard in the autumn, but in later times we find vinegar based condiments. ${ }^{64}$ In the Yuan (1279-1368 CE) imperial dietary Yinshan zhengyao, chives and mustard were apparently used together:

Take five fresh carp and remove the skin, the bones, the head and the tail. Chop very finely 2 liang ${ }^{65}$ fresh ginger, 2 turnips, 1 scallion, coriander and smartweed. Mix with a little fat, grilled mustard, chives, salt and vinegar. ${ }^{66}$

Listing its medical powers, the same imperial dietary classifies carp as:

Sweetish in sapor, cooling, and has poison[ous efficacy]. It is good for coughing, rising counterflow $q i$, and jaundice. It controls thirst and tranquillizes the womb. It regulates oedema and foot $q i$. It should not be eaten after a contagious ailment. Those with chronic asthma cannot eat it. ${ }^{67}$

Li Shizhen first quotes these two established authorities as sources for the carp recipes, then adds his preference for a vinegar condiment with garlic, chopped salted vegetables and ginger. He also adds many medicinal applications, attributing to carp a strong diuretic action. Made into a salad it apparently becomes warming, such that it stops the bowels and cures colds. ${ }^{68}$ On very many occasions, we find him augmenting received wisdom in this way, and without directly challenging his sources, he embellishes or adds localized knowledge and adaptations.

Comments interspersed with quotations from earlier texts expose Li's dilemmas, such as the practicalities of harvesting turtle semen for medicinal purposes:

According to Liu Yu's Xi shi ji 西使記 (Record of the Embassy to the West), this substance comes from the Western Sea. It is the semen of the hawksbill turtle (daimao 玳瓄) which has been swallowed and regurgitated by a shark, and has solidified after many years. It is as precious as gold. There are false substitutes such as rhinoceros faeces. Since it is so valuable, it must have some therapeutic virtue. However, it is uncertain whether this substance is really turtle semen, and there is no way of finding out. I therefore include it here for scholars to verify in future. ${ }^{69}$

Mediating controversy in his sources as to whether turtle meat is heating or cooling by nature, he reveals an intricate experimental knowledge of how the culinary arts combine with the "sapor" of a food, an attribute which is, as we have seen, at once aesthetic and medicinal when understood within the framework of the medical correspondences of the five agent system:

Probably the original nature of the soft-shelled turtle (bie 鱉) is not hot, but when eaten with too many hot things such as pepper and ginger, it loses its original character. Its virtue is lost if it is taken with onions or mulberry wood ash. For eating, one should use small turtles from a sandy river bed. They are beheaded and bled, and boiled with mulberry ash soup. The bones and shell

\footnotetext{
${ }^{64}$ Despeux, op. cit, note 46 above.

${ }^{65}$ This is an ancient Chinese measure, sometimes translated as "ounce" and approximately equivalent to $15.3 \mathrm{~g}$.

${ }^{66}$ Adapted from Buell and Anderson, op. cit., note 17 above, p. 311.
}

\footnotetext{
${ }^{67}$ Ibid., p. 558.

${ }^{68}$ BCGM, vol. 2, 44 juan, pp. 1611-14 passim.

${ }^{69}$ Ibid., 45 juan, p. 1658. Cf Bernard E Read, Chinese materia medica: turtle and shellfish drugs, Peiping, Peking Natural History Bulletin, Dec. 1937 (hereafter Read, Turtles), p. 19.
} 


\section{Vivienne Lo and Penelope Barrett}

are then removed, the water is changed and the turtle is re-boiled. Onions and [soy] sauce are added, to make a thick soup, which is exceedingly good to eat. The gall is pungent in flavour. Broken up and added to the soup it can take the place of pepper and get rid of the rank taste (xingqi 腥氣). ${ }^{70}$

Here we see the gustatory and the medical intertwined in the same remedy. The thermostatic properties of the soft-shelled turtle are transformed with the addition of condiments, and its gall bladder enhances the culinary excellence of the soup. Throughout the text we find similar records of Li Shizhen's personal experience. To our knowledge, he does not set out a theory comparable to Galen's, by which to test and challenge the propositions of medical philosophers of earlier ages. Galen himself pulls his punches with the Hippocratic authors, reserving his best criticisms for the confusions and omissions of later medical authorities. ${ }^{71}$ For him pure reason is the melding of intelligence and training in the naturally gifted, and it is better for the rest of us "to start from experience, and especially because many physicians have declared that the properties of foodstuffs have been discovered by this means alone." 72 Wilkins credits Galen with an intuitive grasp of the tenets of modern epidemiological research methods, reading into his experimentation attempts to "control" all extraneous variables in order to identify the effect of an agent on a dependent variable. ${ }^{73}$ But Li Shizhen's pervasive respect for the authority of his own experience and the experience of his informants goes hand in hand with a constitutional scepticism. Being part of the Ming social and economic transformation, he has been able to read more, travel more widely and meet more people than any of his forefathers, and he is keen to demonstrate it.

\section{What to Eat?}

The cultural question of who we are and what and how we eat lies behind much of Li's preoccupation with food. He is frequently concerned with the limits of the civilized diet and the way foods are eaten by some but are indigestible to others. In the category "humans", these issues naturally come to the foreground.

Moral issues pervade his sections on ren 人 (human beings) and also those on monkeys, apes and supernatural beings, which are all characterized as anthropoid in some way. Citing imperial authority, Li Shizhen condemns anthropophagy-for medicinal purposes or by soldiers "lacking all human feeling" " _ although it is notable that he claims to have included 220 new human recipes among the 287 standard remedies in this chapter. ${ }^{75}$ Speaking of the Xingxing 猩猖 (Orang utan), he states, “if people come to eat them they push the fattest one to the front weeping the while", 76 and of ye nü 野女 (wild women), in an appendix to the same entry, he notes:

[They] have in their kidney a translucent seal ... bearing seal characters. The seal is not unusual

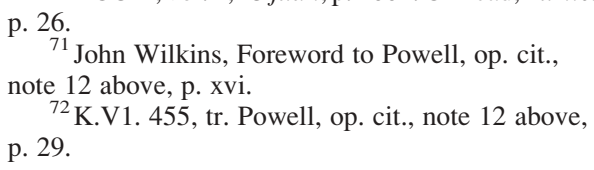

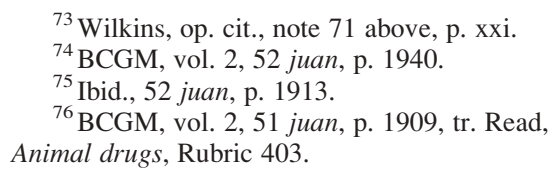




\section{Cooking up Fine Remedies}

because rats' testes also have writing upon them in the seal character, and the Chih Niao (bird) [zhiniao] has a mirror image seal under its wing, all of which must be useful for something though no one knows what. ${ }^{77}$

Li's comments display sensibilities probably appropriate to his social position and religious affiliation. The ingestion of menstrual blood in therapies, he says, is Daoist and "too disreputable to be noticed". ${ }^{78}$ Of human blood he states:

The numerous prescriptions for human blood are improper and impractical. The originators of these ideas are inhuman fellows who probably beget no children. People who follow such nefarious methods, or those who drink human blood mixed with wine should be ignored for God himself [tian 天] will punish them. ${ }^{79}$

He reserves particular disapproval for the use of human bones in medicine, which he represents as impious, degenerate and worse than bestial:

The ancients considered it benevolent and virtuous to cover exposed bones and often received preternatural rewards for doing so. But now wonder-workers, whose hearts are set on profit and the satisfaction of craving, collect human bones to make medicine. Can [medicine,] the "art of benevolence," actually be concerned with this sort of thing? And dogs do not eat the bones of dogs; can it be permissible for men to eat the bones of men ${ }^{80}$

$\mathrm{He}$ is also fiercely critical of family rituals involving eating the human placenta, likening the culprits to wild beasts. Whether this practice is "inhuman" or not, it is found among human societies the world over, and Li's vehement condemnation probably points to a fairly well known culture. But this is a fascinating subject that falls outside the scope of this particular paper. For the moment we leave the reader to contemplate the complexities of Li's belief and practice suggested by his description of harvesting the "human soul" (ren po 人魄)—a tranquillizing drug:

[Shizhen says:] When a man is hung there enters the ground beneath him the anima, which is in form like rotten charcoal which can be dug out of the ground. If not removed it will be the cause of future hangings ... It quietens the heart and spirit of a man. It stills one's fears, and cures delirium. Rubbed to a powder and given with water. ${ }^{81}$

\section{The Culinary Style of Bencao Gangmu}

In comparison to the early materia dietetica outlined in the previous section, we find a far stronger culinary aesthetic pervades Li Shizhen's work. We can see it operating in the rubrics of classification, in the attribution of sources, and in the language, procedures and ingredients that structure the recipes.

It was Li Shizhen's categorization of cai 菜, roughly translated “edible vegetables", that first drew our attention to the theme of how the kitchen arts shaped medical thinking. There

\footnotetext{
${ }^{77}$ Ibid., tr. Read, Animal drugs, Rubric 403A.

${ }^{78}$ Ibid., 52 juan, p. 1931, tr. Read, Animal drugs, Rubric 423.

${ }^{79}$ Ibid., 52 juan, p. 1932, tr. Read, Animal drugs, Rubric 424.

${ }^{80}$ Ibid., 52 juan, p. 1935. Translation quoted from William Cooper and Nathan Sivin, 'Man as a medicine: pharmacological and ritual aspects of
}

traditional therapy using drugs derived from the human body', in Shigeru Nakayama and Nathan Sivin (eds), Chinese science: explorations of an ancient tradition, MIT East Asian Science Series, 2, Cambridge, MA, MIT Press, 2003, p. 248.

${ }^{81}$ BCGM, vol. 2, 52 juan, p. 1934, tr. Read, Animal drugs, Rubric 431. 


\section{Vivienne Lo and Penelope Barrett}

is an ancient dichotomy between terms like shi 食 and fan 飯 which, in their narrow sense, distinguish grains and grain food from dishes of meat and vegetables. A minimum Chinese meal might consist of grain and one dish, whether that be the geng 美 (soup/stew) and millet of early China or rice and zhouzi 肘子 (knuckle of pork) of modern times. Wealth, morality and ritual are all criteria that determine the balance of these two elements in different social and historical contexts. ${ }^{82}$ In Li Shizhen's classificatory system, cai contrasts with cao 草, the wild herbs. These categories are also distinct from those that suggest edible meats, shou 獸, qin 禽 and jie 介—-the four-legged, the avian and the shelled.

Whereas in the preface to his section on grains Li Shizhen simply quotes the standard legends about how Shennong 神農 (the Divine Farmer) taught people how to cook their food and thereby civilized humanity, the preface to the cai section refers to the work of dietary physicians and suggests that the plants in this category assist the grains through the nourishing medical properties of the five sapors. ${ }^{83}$ Despite this promising start, the "edible vegetable" preparations are not mundane foods and did not yield many recipes of interest for the relationship between cuisine and medicine. They are mostly decoctions, pastes to be administered topically and via the nose, and other medically inspired preparations. The intention appears to be to extract the active ingredient and deliver it in the most palatable way possible. Rather than being localized in any particular category, it seems that recipes of special culinary interest are to be found throughout Bencao gangmu, at the organizational level of the 'Appended recipes', which we will examine more closely below.

\section{The Appended Recipes}

If Li's main impulse was the evidential scholarship of a Confucian textual scholar involved in $g e w u$ 格物 (investigation of things), this was not his only manner of engagement with his subject. ${ }^{84}$ Certainly, Li's eclectic attitude led to innovations in classification and in the ordering of each of the monographs in his materia medica. Adding to the traditional categories that allow for terminological variants for each substance, its collection, its geographical environments and distribution, information relating to its morphology, medical properties, and therapeutic action and uses, Li newly created a section called fufang 附方 (Appended recipes) wherein we can begin to get a sense of the depth of his personal research. ${ }^{85}$

Fufang is a rubric under which Li's own more practically oriented researches are gathered together, with the application of recipes and remedies quoted from many well known ancient and medieval authors such as Tao Hongjing 陶弘景 (452-536 CE), Ge Hong 葛洪 (281-341), Sun Simiao 孫思邀 (c.581-682) and Su Song 蘇頌 (1020-1101). Reference to recipes can be found in other sections of each entry but fufang is the place where we find the unattributed culinary recipes together with his personal appreciations and evaluations. Here he proudly enumerates how many recipes he has added to each section. By his own admission, Li has added fifteen new recipes to the five for pork meat that he has adopted from earlier sources. The 'Appended recipes' to his entry on pork illustrate how he serves

\footnotetext{
${ }^{82} \mathrm{~K}$ C Chang, 'Ancient China', in Kwang-Chjih Chang (ed.), Food in Chinese culture: anthropological and historical perspectives, Newhaven, Yale University Press, 1977, pp. 40-1.
}

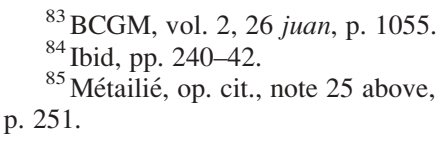




\section{Cooking up Fine Remedies}

up pleasing foods with medical recommendations, and intersperses comments expressing his own personal taste and medical observations with those of previous authorities:

For dysentery with refusal to eat:

Use dried cured pork. Simmer slowly till done, and eat. Wondrous. Recipe from Li Lou 李樓.

For rising Qi, coughing, feelings of distress, wheezing:

Cut up pork and make into a patty (duizi). Fry in pork lard. Eat. Xin shi yi jing 新食醫鏡 (New Mirror of Nutritional Medicine)

For floating oedema, distention, loss of appetite and feeling of oppression:

Use meat from the back of the pig. Cut up the raw meat. Eat with garlic and scallion. (New Mirror of Nutritional Medicine)

For swelling of the body, attacking the heart:

Use raw pork. Marinate in starch solution. Squeeze dry and cut into slivers. Eat with garlic and scallion. Take twice a day. Brings down Qi and expels wind. This is a foreign recipe. Recipe from Zhang Wenzhong 張交仲.

For wounds and wind swelling:

Use freshly slaughtered pork. Cut into slices while still warm. Stick on to the affected part. Apply three slices in succession, and the swelling will go down. Simple and convenient.

For white tiger wind sickness:

Use three skewers of pork. Combine with $1 \mathrm{ge}$ of hempseed, $1 / 2$ cup of wine, hold in the mouth so as to apply by spraying from the lips. Apply the meat to the affected part, chanting as follows ...

For wind madness with singing and laughing and walking about without rest: ${ }^{86}$

Use 1 jin $^{87}$ pork. Boil till cooked and cut into slivers. Eat with soy sauce and vinegar. ${ }^{88}$

Pork, we learn, has the medical properties of being bitter, somewhat cooling and slightly poisonous and was used for chronic madness. Here we find pork recipes for a number of diseases associated with wind, long thought to be an external cause of madness and acute disease. $^{89}$

In early China tomb literature we began to see a culinary aesthetic emerging in the aphrodisiac and longevity recipes. In all of Li's pork recipes quoted above there is evidence of culinary skill, but two of the remedies are to be topically applied. So how far does the greater attention paid to food preparation for the purposes of pleasure extend? Can we distinguish the culinary from the medical by descriptions of the softness of the meat or its saturation with flavour, by references to the addition of flavouring ingredients, to colour, to the adjusting of heat or cooking methods? Or is the identification negative, in the sense that a kitchen recipe is by default not a decoction, infusion or tisane designed for ease of application rather than for pleasure, a preparation that is eaten and savoured rather than applied topically or via the nose? The 'Appended recipes' section for scallion bulb in

\footnotetext{
${ }^{86}$ In a personal communication, Geoffrey Lloyd has drawn attention to a similar association between singing and madness in some Greek diagnoses. Cf. Lloyd, op. cit., note 13 above, p. 21.

${ }^{87}$ This is an ancient Chinese measure, sometimes translated as "pound" and approximately equivalent to $0.5 \mathrm{~kg}$.
}

\footnotetext{
${ }^{88}$ BCGM, vol. 2, 51 juan, p. 1770.

${ }^{89}$ Shigehisa Kuriyama, The expressiveness of the body and the divergence of Greek and Chinese medicine, New York, Zone Books, 1999, pp. 233-42.
} 


\section{Vivienne Lo and Penelope Barrett}

chapter 26 gives us further examples of medical preparations that will serve as a point of contrast to Li's culinary recipes. Li Shizhen states that he has compiled fifteen old recipes and inserted eight new ones. Here is a selection where he is quoting from early and medieval Chinese literature:

Zhang Zhongjing's 張仲景 snake gourd and scallion soup:

... Use 1 snake gourd fruit, $1 / 2$ sheng scallion bulb, 7 sheng distilled liquor. Boil till reduced to 2 sheng. Administer in 2 doses.

Zhouhou 肘後 [Zhouhou beiji fang 时後備急方 (Emergency Prescriptions to Keep up your Sleeve)]: To cure recurrent xiong bi (pressure in the chest):

Use 5 sheng scallion root. Liquidize by pounding and drink it. Recovery will be immediate. ${ }^{90}$

In another recipe from Zhouhou, also recorded here, it is said to be preferable if the liquidized scallion is taken via the nose. ${ }^{91}$

Representative of the jiu 非, "chives" section, where Li states he compiles twelve old recipes and inserts twenty new, is the following recipe, quoted from Shiliao bencao 食療本草 (Materia Medica for Dietary Therapy):

For xiong bi with intense pain:

.. Take 5 jin raw chives or chive roots. Wash and liquidise by pounding. Administer. ${ }^{92}$

These three recipes require techniques of decoction and extraction typical of the "edible vegetables" section. Other recipes in this section, such as the following treatment "for Yin Yang yi bing, inflammation of the yin [i.e. penis] in men, colicky pain in the lower abdomen, a heavy head and blurred vision", from Shiliao bencao, require the preparation of pastes:

.. Boil it in a soup of jiashu 层鼠 (a kind of rodent) droppings. ${ }^{93}$ Use 14 rodent excreta, 1 large handful of chive bulbs, 2 wine cups of water. Boil for 7 minutes. Remove the sediment and fry. Administer warm. If a sweat is produced, the patient is recovering. If there is no sweating, administer once more. ${ }^{94}$

The following recipe, quoted by Li from Beiji qianjin yaofang, "to cure xiong bi (pressure in the chest)" is a decoction that is more of a "soup stock" than a medicinal preparation. On the other hand, the ingredients are processed by "biting and chewing" ( $f u j u$ 吹咀), a method from the repertoire of drug manufacture:

\section{Pinellia and scallion decoction}

Use: 4 liang scallion bulbs, 1 ge (decilitre) pinellia, $1 / 2$ liang zhishi (trifoliate orange), 1 liang fresh ginger, $1 / 2$ snake gourd. Bite and chew. Boil with 3 sheng of "plain minced meat sauce" (?), until reduced to 1 sheng. Administer warm, 3 times a day. ${ }^{95}$

Yet we must be wary of drawing very hard and fast boundaries. Pharmacological techniques have always drawn from the culinary arts for the purposes of making a remedy

${ }^{90}$ BCGM, vol. 2, 26 juan, p. 1069.

${ }^{91}$ Ibid.

${ }^{92}$ Ibid., 26 juan, p. 1059.

${ }^{93}$ This use of excreta clearly signals that this is a medicinal preparation rather than a culinary one.

However it does not seem to fall into the category of "shocking remedies" like the Dreckapotheke of
Greco-Roman medicine, or to carry the same associations of driving out pollution by means of pollution. Cf., for example, Heinrich von Staden,

'Women and dirt', Helios, 1992, 19: 7-30.

${ }^{94}$ BCGM, vol. 2, 26 juan, p. 1059.

${ }^{95}$ BCGM, vol. 2, 26 juan, p. 1069. 


\section{Cooking up Fine Remedies}

palatable to the patient. From Han times, remedy literature found in Dunhuang military deposits testifies to complex prescriptions, the largest number of ingredients in a single remedy being fifteen. Preparation of the drugs includes making decoctions, pills, pastes, powders, tinctures, drops and roasting. One example involves steeping in pure wine, egg yolk, and then "stirring three hundred times". For ease of swallowing, milk, camel milk, pork fat, and white honey are used to thin the medicines. Methods for administrating the medicine include internal applications, fermented drinks, rice water drinks, vinegar sauce drinks, bean water drinks, and drinks made with saliva. ${ }^{96}$

Yet Li Shizhen's own culinary work is very different from earlier materia dietetica, not only in its sophistication, but also in the way in which it combines intellectual rigour and breadth of reference with an intense personal response to his material. Here, he touchingly records how a fragrant aroma can make a nutritional remedy positively attractive to a child with acute diarrhoea:

For diarrhoea after eating and dysentery in infants, where the condition is so serious that the child keeps its eyes closed and cannot eat:

Use 1 liang prime pork. Cut into thin slices and roast till fragrant. Take 1 qian of grease powder(?), sprinkle it on, and get the patient to eat it. Or else hold it under the patient's nose so that he or she can smell the fragrance, and he or she will naturally feel like eating it. ${ }^{97}$

Interspersed through the 'Appended recipes', we find records of unattributed recipes together with personal interjections, such as: crabs are "excellent for salting", 98 or "sea coast people break open the shells [of oysters] and extract the meat which is toasted for food of the finest flavour [sapor] and most nutritious. It is the best sea food". 99 The meat of the abdomen of one type of turtle "tastes like sheep's tripe and can be eaten". ${ }^{100}$ These comments draw the reader into imagining the scope and range of Li's forays into the kitchen, his network of acquaintances, and his conversations with chefs, women and travellers from other parts.

\section{Personal Preferences}

Li Shizhen's work is a rich source of information about regional variation in culinary aesthetic. Through his fieldwork, he complements his scholarly research, although we suspect that he often uses his knowledge to reinforce personal preference and regional bias. Much of the information seems value-free, such as the observation that “Ling yang 罍羊 (a kind of antelope) is regularly eaten by northerners but southerners only take it to prevent injury from snakes and insects", ${ }^{101}$ or that huang shu 黄鼠 (gerbils) are a common food of the north and so "fat and tasty and crisp like suckling pig" that in the Liao, Jin and Yuan dynasties, "people reared them on goats" milk and sent them to the court as a food". 102

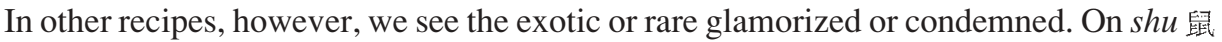
(mouse/rat), he states with barely concealed contempt that "the Cantonese like to eat them,

\footnotetext{
${ }^{96}$ Xie Guihua, 'Han bamboo and wooden medical records discovered in military sites from the northwestern frontier regions', in Lo and Cullen (eds), op. cit., note 23 above, pp. 78-106, esp. pp. 84-8.

${ }_{97}$ BCGM, vol. 2, 50 juan, p. 1770.
}

\footnotetext{
${ }^{98}$ Ibid., 45 juan, p. 1665.

${ }^{99}$ Ibid., 46 juan, p. 1669.

${ }^{100}$ Ibid., 45 juan, p. 1657

${ }^{101}$ Ibid., 51 juan, p. 1863.

${ }^{102}$ Ibid., 51 juan, p. 1903.
} 


\section{Vivienne Lo and Penelope Barrett}

but prefer to call them domestic deer". ${ }^{103}$ And in his description of the southern delicacy of smoked or salted macaque, a domestic animal whose indiscriminate diet of leftovers renders it useless in medicine, he implies that southerners are less discerning. ${ }^{104}$ The impression is reinforced by scattered comments, such as: southern pork "yields a thick deleterious gravy" in comparison to the northern thin gravy. ${ }^{105}$ Social distinctions are also frequently reinforced through culinary trope, although the exotic is not exclusively the preserve of the élite; peasants for example, "like to eat pelican meat and use its fat in medicine". 106

The quality of being "outer" or "foreign" is attributed by Li to the southern regions, since the littoral south was beginning to challenge the Silk Roads as the gateway for international influence in the sixteenth century. Many of the ingredients now associated with regional Chinese cuisine originated in the New World and arrived through the coastal areas of Fujian and Guangdong during Li's lifetime. ${ }^{107}$ Sweet potato is apparently delicious either steamed or roasted: "People living in the [South China] sea enjoy great longevity because they eat sweet potatoes instead of the five grains." 108 Not all foreign foods rank as delicious for him. On corn maize "Shizhen says: Maize is a species from the west, and few people cultivate it."109 Strangely, there are no entries on peanuts or on potatoes. And despite references to chilli in sixteenth-century literature, Li does not mention it; nor indeed did it make its enduring impact on the cuisine of Sichuan, Hunan and Yunnan until the eighteenth century. ${ }^{110}$ But the economic changes of the Ming centred on the Yangzi river area fostered a new pan nationalism that is reflected in his commentaries. "Shizhen says: The loofah (sigua 絲瓜) was unknown prior to the Tang-Song period, but now it is found in the north and the south [all over the empire]."111 And again, "although the Balsam pear [momordica charantica, kugua 苦瓜] originates from the foreign countries to the south, it is now widely cultivated in the Fujian area". ${ }^{112}$

A recipe may also reflect a sentiment or nostalgia for time and place conveyed in a distinct literary style, through quotation or attribution. Eulogizing the $y i$ zhi 翟鳥雉 (long tailed pheasant) in his section on the "plains birds" he states:

Its flesh is finer than that of a partridge, as the old proverb states, "among quadrupeds venison is the finest food, among bipeds the Ch'iao [qiao, a 'larger bird', used here apparently as a superordinate term] stands first in flavour."113

Most notably, it is when we get to the meat, game bird and seafood recipes that we see evidence of sophisticated culinary skill with a concern for flavour and texture expressed in

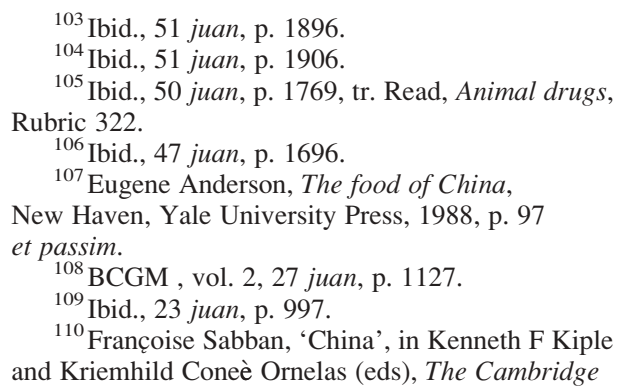

world history of food, 2 vols, Cambridge and New York, Cambridge University Press, 2000, vol. 2, pp. 1165-75, on pp. 1169-71; see also Zheng Jinsheng, 'Dietary hygiene and allied literature in the Ming dynasty of China', www.cintcm.com/e cintcm/e forum/ dietary $\% 20$ hygiene $\overline{\%} 20$ and $\% \overline{2}$ allied $\%$ 20literature.htm

${ }^{111}$ BCGM, vol. 2, 28 juan, p. 1143.

${ }^{112}$ Ibid., 28 juan, p. 1145.

${ }^{113}$ Ibid., 48 juan, p. 1728, tr. Read, Avian drugs, Rubric 270. 


\section{Cooking up Fine Remedies}

a language that transcends medical significance. Words describing fine or delicious food reflect Li's general enthusiasm. We find frequent allusions to the sensual pleasures of food, in which expository prose gives way to description or narration of the eating experience; for example, gerbil meat is "extremely succulent and delicious, and crisp like sucking pig". ${ }^{114}$ Food is given an olfactory or gustatory grade ranking on a scale that begins with having little or no taste, and ranges through strong, earthy, goaty and rank. He often describes taste through analogy-one thing tastes like another, or is stronger, finer, coarser, etc.

The preface to the "birds" section says that (probably on account of being sky-borne) birds are eaten for their "Yang" properties, but the coincidence of flavour and potency goes beyond the medical. The Tu qiu (adjutant bird), for example, is "best roasted. As a dried meat it is a delicacy making one so strong one can run like a horse". ${ }^{115}$

Li has strongly stated personal preferences, which are nowhere clearer than in his ode to the crab:

Fresh crabs are served with ginger and vinegar, accompanied by strong liquor. One should savour the roe, then break open the claws. In small quantities they are delectable and surely not harmful. But gluttons will consume a dozen or more at a sitting together with various kinds of meat and other foods. They eat and drink twice as much as they need ... then blame [their upset stomachs on] the crabs. But why blame the crabs? ${ }^{116}$

He has much to say about the virtue of different meats:

Tiger meat is coarse in flavour and not delicious. It is somewhat more palatable when salted. ${ }^{117}$ The meat of the wild horse "is said to be like ordinary horsemeat". ${ }^{118}$

Cat meat is "inferior to wild cat ( $l i$ 狸) as a food". ${ }^{119}$

Wild cat "tastes not dissimilar to fox-meat ..." although "the species ... called ...Mao Li [貓狂, cat $l i] \ldots$ stinks and the flesh is inedible, there is another kind . . called ...Hu Li [ 虎狸, tiger $l i] \ldots$ whose flesh is sweet and good to eat." 120

Wolf "has a stronger flavour than dog or fox meat" ${ }^{121}$ while the common rabbit/hare makes "firstclass food" 122 and yinshu 隱鼠 (tapir mole) "is edible and tastes like beef". ${ }^{123}$

Among the swans, the flesh of bu neng ming $e$ 不能鳴 鵝 (the mute swan) “is slightly rank and far inferior to that of da jintou e 大金頭鵝 (the Tundra Swan)"; the baoru 铇鴑 (eastern buzzard) is "fleshy and fat with coarse but tasty meat"; ${ }^{124}$ the tree sparrow is good roasted or pickled. ${ }^{125}$ On ducks, Li Shizhen tells us that he prefers green-headed $f u$ 鳥 ducks (mallard) to the short-tailed variety ${ }^{126}$ and warns against eating the meat in the tail of $m u$

\footnotetext{
${ }^{114}$ Ibid., 51 juan, p. 1903.

${ }^{115}$ We have followed Read's translation since, despite an apparent error in transcription, he identifies the bird from the characteristics listed (a bald and vicious water bird). BCGM, vol. 2, 47 juan, p. 1695, tr. Read, Avian drugs, Rubric 249.

${ }^{116}$ BCGM, vol. 2, 45 juan, pp. 1665-6.

${ }^{117}$ Ibid., 51 juan, p. 1848.
}

${ }^{118}$ Ibid., 51 juan, p. 1857.
${ }^{119}$ Ibid., 51 juan, p. 1880.
${ }^{120}$ Ibid., 51 juan, p. 1882
${ }^{121}$ Ibid., 51 juan, p. 1888.
${ }^{122}$ Ibid., 51 juan, p. 1889.
${ }^{123}$ Ibid., 51 juan, p. 1902.
${ }^{124}$ Ibid., 47 juan, p. 1699.
${ }^{125}$ Ibid., 47 juan, p. 1733.
${ }^{126}$ Ibid., 47 juan, p. 1702. 


\section{Vivienne Lo and Penelope Barrett}

ducks. ${ }^{127}$ Chun 鴊 (quail), as we saw at the head of this paper, stands out for fine treatment. ${ }^{128}$ Yan 騴 (eastern quail) “is soaked in wine with smartweed, and then steamed to cook tender", 129

Under sheep/goat (yang 羊), we find illustrations of the Han concern for ways to neutralize the distinctive flavour of mutton:

Animals which have wool that is too downy have a strong goaty taste (shan 膳). Ovine meat is said to be tenderized by cooking with apricot kernels (xing ren 杏仁) or broken tiles (wapian 瓦片); walnuts remove the rank taste; a bamboo rat improves the flavour. ${ }^{130}$

Bamboo rat "is as large as a rabbit and often eaten for food, tasting like duck meat". It is emphasized as the pre-eminent meat tenderizer; and Li Shizhen quotes a proverb to the effect that bamboo rat softens mutton when the two are cooked together, just as terrapin is made tender by adding a few mosquitoes. ${ }^{131}$

Correct identification of ingredients is an essential part of medical practice. In an expanding market economy and cosmopolitan environment, that skill required travel and worldliness. Thus in the second century, we find Galen working across vast areas and travelling explicitly to identify species of wheat. Both Galen and Li Shizhen claim authority and status through travel and knowledge of how the international and local environments interact. We have seen in the raw fish recipes and the references to the Eight Treasures how allusion to foodways of the ancients served to align $\mathrm{Li}$ with great literary traditions. A panoramic knowledge of contemporary cuisine then could appropriate everything within the limits of the known world to legitimate his materia medica. This was a time-honoured practice. In the previous dynasty, the Mongol emperors had celebrated their mastery of the universe with spices from every corner of Central Asia-and before that the Song court moved around China assimilating local characteristics to the notion of imperial cuisine.

\section{From Study to Kitchen?}

In the Sun Simiao/Meng Shen model for the development of materia dietetica, the medicalization of food is a phenomenon related to the compiling of materia medica for medical compendia. If, then, the impulse came from above, from the scholar physicians, we might reasonably enquire how widely culinary knowledge of the medical power of the five sapors was really put into practice. Could medicinal foods be just a bookish fantasy about imperial cuisine that began in ancient times with the seasonal aesthetic of the shi yi 食醫 (dietary physician) in the idealized bureaucracy described in Zhou li 周禮 (Ritual of Zhou) (?fourth/ third century BCE)? Are they part of a fantasy that passes through the medicalization of Middle Eastern and Steppes' foodways evident in the fourteenth-century 'Propriety and Essentials in Eating and Drinking', where we find Hu Sihui deliberating on wolf meat?

Ancient Pen-ts'ao [i.e Bencao, materia medica] do not include entries on wolf meat. At present we state that its nature is heating. It treats asthenia. I have never heard that it is poisonous for those

${ }^{127}$ Ibid., 47 juan, p. 1700.

${ }^{128}$ Ibid., 47 juan, p. 1731.

${ }^{129}$ Ibid. Smartweed, or water pepper, is also listed as a culinary and medicinal herb used by Culpeper.

\author{
${ }^{130}$ BCGM, vol. 2, 50 juan, p. 1791 \\ ${ }^{131}$ Ibid., 51 juan, p. 1902. \\ See Read, Animal drugs, Rubric 392.
}




\section{Cooking up Fine Remedies}

eating it. In the case of the present recipe we use spices to help its flavor. It warms the five internal organs, and warms the center. ${ }^{132}$

How did Hu Sihui resolve this problem and make such definite statements about the medical properties of wolf? Without previous authority, we find him apparently relying on hearsay. In our own time, are the modern day European and American manuals prepared for the Western practitioner of Oriental medicine the latest manifestation of the same scholarly indulgence ${ }^{133}$ - a nutritional Orientalism that never truly diffused into Chinese popular culinary practice? Or was there an upward diffusion of knowledge though society? Is it the case that "If physicians had to know cookery, lay people were expected to have knowledge of the therapeutic properties of food"? ${ }^{134}$ Is there then a culinary aesthetic that passes from private or regional kitchens into medical recipes? Are the élite collectors of recipe manuals and the scholar physicians of later times really such eclectic assimilators of folk tradition?

Looking more closely at Hu Sihui's comment on the nature of wolf, we find that he is prepared to listen to the authority of rumour in the interests of health and safety. Undoubtedly, extremely poisonous foods leave traces of their efficacy for all to see. We can trace here the process through which properties are assigned to foodstuffs, from analogy within a system of knowledge to testable hypothesis. One can appreciate how the assignation of "heating" as a quality might be determined through analogy with the action of other, more familiar, red meats, or through a consideration of the lifestyle of the wolf, or analysis of the dietary requirements of northern nomads, who no doubt needed to keep warm during the harsh winters. Once the first analogies are made and qualities established, other more specific indications automatically follow, so that a "heating" food will warm the inner organs, etc. The hypothesis can then be tested against reality. Thus by the time Li Shizhen came to write Bencao gangmu, he was able not only to state unequivocally that wolf meat is salty, heating and non-poisonous, but also to describe its taste (which is "better than dog or fox"). ${ }^{135}$

Nowadays there is a growing anthropological literature about food in China. ${ }^{136}$ Ordinary middle-aged people in contemporary Beijing have a great fund of knowledge about the medicinal properties of food. Some foods are clearly more medical than others, and some medical properties, such as that "mussels eaten in too great a quantity will generate cold", ${ }^{137}$ may appear more obvious than others. To establish the degree and depth to which scholarly knowledge of the medical properties of food, or medical cuisine, diffused into society is much more difficult for the Ming period, for there are far fewer domains across which we can conduct that research. One important source for understanding the role of diet in Ming medical practice, not yet fully explored, is the new genre of case history collections in the Ming period. This new literature supplemented the classical medical treatises, which were by that time widely available to the new class of scholar physicians.

\footnotetext{
${ }^{132}$ Translated in Buell and Anderson, op. cit., note 17 above, p. 295.

${ }^{133}$ See, for example, Zhuo Zhao and George Ellis, The healing cuisine of China, Vermont, Healing Arts Press, 1998.

${ }^{134}$ Wear, op. cit., note 2 above, p. 170.
} 
In her study of Wang Ji’s 汪機 Shi shan yi’an 不山醫案 (Stone Mountain Medical Case Histories), Joanna Grant finds a gender bias for an aetiology of "excess" attributed to nearly one in ten male cases, who are most likely to be suffering from over-indulgence in sex, alcohol or food. As with the Han case histories, she suggests that this is a form of remonstration by the physicians against a society perceived as in decline. ${ }^{138}$

Sources available for the Ming period élite lifestyle also include the new genre of novels, embracing adventure stories, erotica, and tales of privileged family life. Earlier literature, such as the Tang short stories, contains some references to medicinal foods, but these are few and far between. In the following extract, the courtesan Li Wa 李娃 ministers to her hapless scholar:

Then she gave the young man a bath and changed his clothes. First she made soup and rice-gruel to ease his bowels, and next nourished his system with milky drinks. Only after ten days or more did she serve him a full diet of land and water produce.... Within a few months he had put on a little flesh. At the end of a year he had recovered his normal strength. ${ }^{139}$

Rigorous research of the Ming literature remains to be carried out, but from a superficial survey it seems that popular knowledge of the medicinal effects of food was not schematically aligned with correlative medicine. To be sure there is the odd reference to plums strengthening the lungs, or food to help digestion. ${ }^{140}$ Rather, most references are to warming foods for preventing post-partum cold, milky drinks to strengthen the body, or foodways traditionally associated with longevity practice, and the immortals.

Most remarkable is the coincidence of allusions to food, sex and medicine in Roupu tuan 肉蒲團 (The Carnal Prayer Mat):

"Talent and looks," said the Knave, "are sweeteners for the medicine of seduction. Like ginger and dates, their flavor helps get the medicine inside, but once it's in there, the medicine alone has to cure the disease; the ginger and dates are of no further use ..."

Before I go under the knife, I ought to take this chance to find a woman and have a bout or two with her. It would act like a dose of rhubarb and purge all the emotional congestion from my system. ${ }^{141}$

\section{Conclusion}

We have managed to establish unequivocally that Li Shizhen was a gourmet par excellence. That his culinary knowledge and experience brought shape, structure and culture to Bencao gangmu is evident in the ease with which we can distinguish broad-if interpermeable — categories of culinary and medical remedies and discourse. It is evident in his tasty remedies and in the pervasive language of pleasure and disgust, a language that derives from a wider aesthetic appreciation of food, and is distinct from the medicalized treatment of "sapor". Fine food inspired him to personal rhapsodies that are

\footnotetext{
${ }^{138}$ Joanna Grant, op. cit., note 51 above, pp. 116-40, passim.

${ }^{139}$ Glen Dudbridge, The tale of Li Wa: study and critical edition of a Chinese story from the ninth century, London, Ithaca Press, 1983, p. 167.
}

\footnotetext{
${ }^{140}$ Christopher Cullen, 'Patients and healers in late imperial China: evidence from the Jingpingmei', Hist. Sci., 1993, 31: 99-150, p. 108.

${ }^{141} \mathrm{Li} \mathrm{Yu}$, The carnal prayer mat, trans. Patrick Hanan, New York, Ballantine Books, 1990, ch. 6 , p. 100 ; ch. 8, p. 120.
} 


\section{Cooking up Fine Remedies}

qualitatively different from anything he writes in other contexts, wherein we find much of the spirit of the man, his personal preferences and pleasures.

Li Shizhen's different categories bore very different results for our inquiry. While metals and minerals, clothes and trees would seem to have little to offer an investigation into the culinary, the remedies from turtles, birds, scaly and shelled creatures, and quadrupeds provided commentaries on what is good to eat, how and when. We can say with confidence that Li listened to the stories and accounts of life in the kitchens around him, and those of his friends and collaborators; that he was familiar and comfortable with the identification and differentiation of common and rare foodstuffs; that he knew the language and processes of food preparation; and that mastering these skills formed a substantial part of the research activity involved in his overall project to compile a comprehensive materia medica.

There is, however, a more serious academic point to be made, beyond the simple observation that Li Shizhen liked food and knew a lot about it. Many of the culinary recipes appear to be from Shizhen's own hand. He collects them together, for the most part, under his new rubric of the 'Appended recipes'. In many respects, the language and research methods involved in compiling this recipe collection are identical to those employed in pharmacology, but parts of the culinary sphere lay beyond the world of his study, the drug stores, and the market place. Unlike the soft medical traditions of the kitchen disparaged as "huckstery" by van Helmont, participating in Chinese haute cuisine also linked the scholar to a lofty tradition of power and position that we have traced to Warring States literature.

In a rapidly changing and economically expansive world that permitted social mobility, publishing was one way for Li Shizhen to claim authority for himself. That authority was enhanced immeasurably by mastery of the culinary spheres, which uniquely allowed him to claim higher authority, and through expert knowledge of food from every corner of the Ming empire, to appropriate that authority to himself. This was a grandeur to which pharmacological allusion alone would not admit. Food was just that much more posh, since as we have shown, "one of the most important qualifications of a Chinese gentleman was his knowledge and skill pertaining to food and drink". ${ }^{142}$

Whether Li Shizhen's insights derive primarily from first-hand experience of decocting, infusing and cooking, or from the aesthetic appreciation engrained in the well-to-do Confucian scholar, in his commentaries one can detect something of the same spirit of fun, curiosity, and self-improvement that embellished the intellectual pursuits of the European naturalist-collectors from the sixteenth century onwards. ${ }^{143} \mathrm{He}$ certainly relished the testimony of chefs, cooks and travellers as he gathered up fine remedies and popular knowledge from all over China. Even though he may have been like Mencius' gentleman who "distances himself from the kitchen", his own hands unsullied with the dirty business of cooking, we cannot dismiss his commitment as anthropological curiosity. His engagement with and investment in the efficacy of his remedies was much more intimate and immediate, qualities evident when he vouches for the practice of harvesting of the human p. 11 .

${ }^{142}$ Chang (ed.), op. cit., note 82 above,
${ }^{143}$ Fa-ti Fan, 'Victorian naturalists in China: science and informal empire', Br.J. Hist. Sci., 2003, 36 (1): 1-26, p. 14. 
soul. Yet, he brought to his work a critical eye and a belief in the authority of his own personal evaluation of ancient sources and "common knowledge", no doubt a confidence supported by the new status of élite scholar physicians in Ming times. His voice is nowhere stronger than in his rhapsodies about good food, and his appreciation of the importance of nutrition as a powerful and legitimate medicine is one organizing factor in the innovative structure of his materia medica. As the sixteenth-century debate about the efficacy of gentle remedies raged in Europe, on the other side of the world Li Shizhen was proud to be the cultural ambassador for the kitchen, all-round consumer and scholar of the culinary and medical arts. 